\title{
ЗАСТОСУВАННЯ НАВЧАЛЬНИХ ПОСІБНИКІВ 3 САМОСТІЙНОӤ РОБОТИ СТУДЕНТІВ І ПОРТФОЛІО В НАВЧАЛЬНОМУ ПРОЦЕСІ НА КАФЕДРІ ОРТОПЕДИЧНОЇ СТОМАТОЛОГІї ОНМедУ
}

\author{
Л. Д. Чулак, А. О. Бас, В. Г. Шутурмінський \\ Одеський національниймедичний університет
}

\section{APPLICATION OF TUTORIAL WITH STUDENTS INDIVIDUAL WORK AND PORTFOLIO IN EDUCATIONAL PROCESS AT THE DENTISTRY DEPARTAMENT OF ONMEdU}

\author{
L. D. Chulak, A. O. Bass, V. H. Shuturminskyi \\ Odesa National Medical University
}

\begin{abstract}
У статті подано досвід організації самостійної роботи студентів на кафедрі ортопедичної стоматології Одеського національного медичного університету.

3 метою контролю якості самостійної позаурочної роботи та відпрацювання практичних навичок студентами стоматологічного факультету викладачами кафедри розроблено серію навчальних посібників з курсу ортопедичної стоматології, що дозволяє оцінювати роботу студента та контролювати її виконання поза класом. Також розроблено систему портфоліо для контролю освоєння практичних навичок і об’єктивізації модульної оцінки студентів.

The article describes the experience of independent work of students at the Department of Prosthetic Dentistry of Odesa National Medical University.

In order to control the quality of self-extracurricular work and practical skills for students of Dental Faculty the lecturers developed a series of textbooks for the course of Prosthodontics, that allows to evaluate student work and monitor its performance outside of class. Also, the system of portfolio is to control the development of practical skills and objectification modular evaluation of students.
\end{abstract}

Вступ. Сучасний рівень розвитку і збільшення обсягу знань у всіх напрямках медичної науки і зростаючі вимоги до системи підготовки висококваліфікованих фахівців потребують вдосконалення існуючих та пошуку нових навчальних технологій і методичних прийомів у навчальному процесі [1].

У рамках переходу вищої медичної освіти на кредитно-модульну систему навчання, на самостійну роботу студентів, згідно з новим навчальним планом відводиться близько 1/3 всіх навчальних годин [2].Тому стають особливо актуальними питання організації та удосконалення самостійної роботи студентів.

Зметою організаціїта активізаціїсамостійної роботи студентів на кафедрі ортопедичної стоматології ОНМедУ розроблені “Навчальні посібники СРС” (рис. 1).

Основна частина. Розроблені співробітниками кафедри “Навчальні посібники СРС" містять завдання модуля, тематичний план (у повній відповідності до типової програми), вимоги до виконуваних студентами завдань, форми поточного та підсумкового контролю, перелік питань і практичних навичок, що виносяться на модульний контроль, список рекомендованої літератури (рис. 2-4).

Тема кожного заняття містить такі елементи:

1. Цілі заняття.

2. Зміст теми.

3. Орієнтовна карта для позааудиторної самопідготовки студента.

4. Тестові завдання.

5. Рекомендована література.

6. Аудиторна робота.

7. Практичні навички.

Цілі заняття - багаторівневі - дають уявлення викладачам і студентам про те, з якими питаннями необхідно ознайомитися студентам, які теоретичні знання вони повинні набути (вивчити) і якими практичними навичками оволодіти (рис. 2).

Зміст теми - перелік теоретичних питань, освітлюваних у темі. Якість теоретичної підготовки студентів до теми оцінюється викладачем 3 цих питань під час співбесіди на занятті (1 етап навчання: запам’ятовування інформації). 


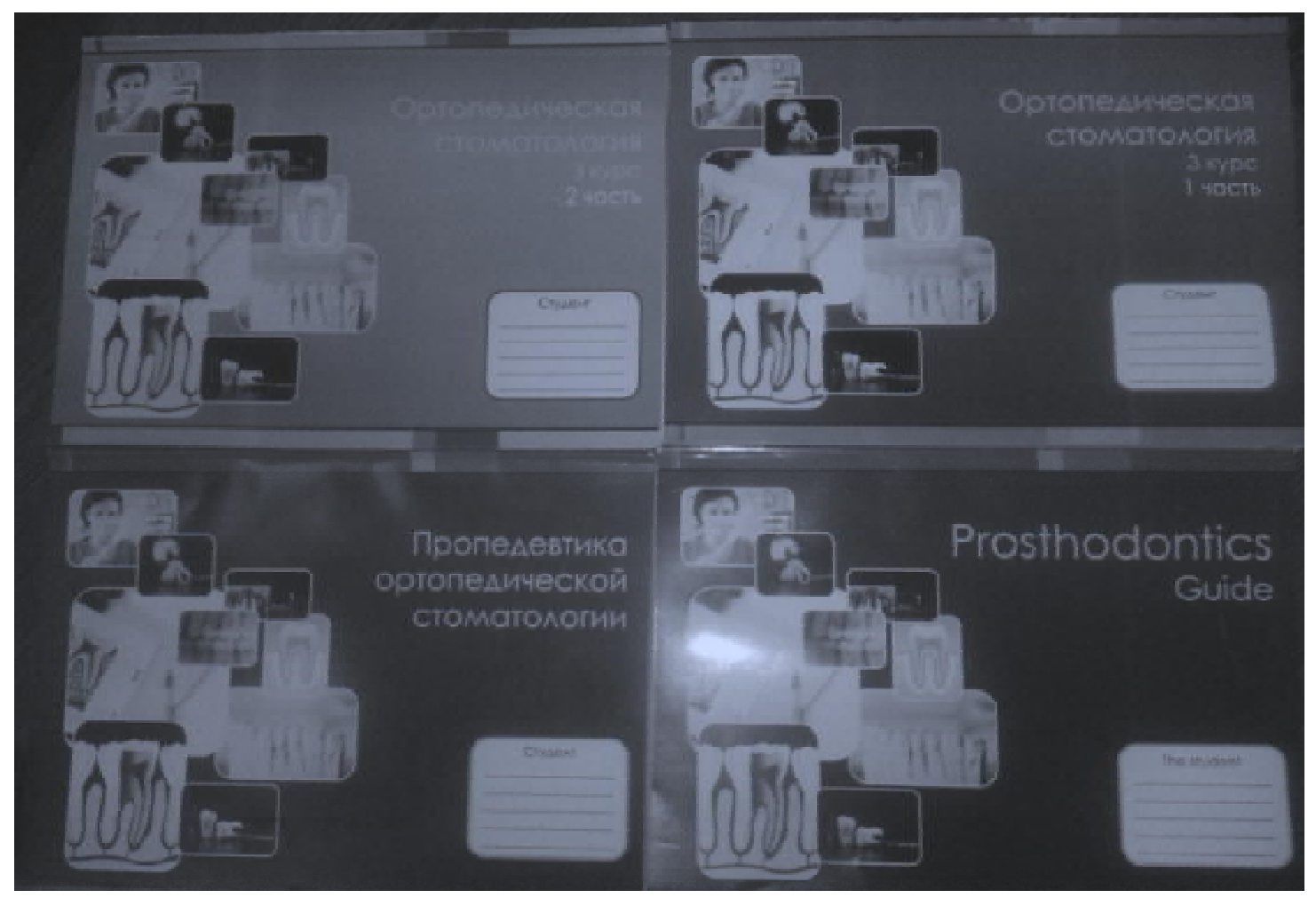

Puc. 1. Навчальні посібники для самостійної роботи студентів.
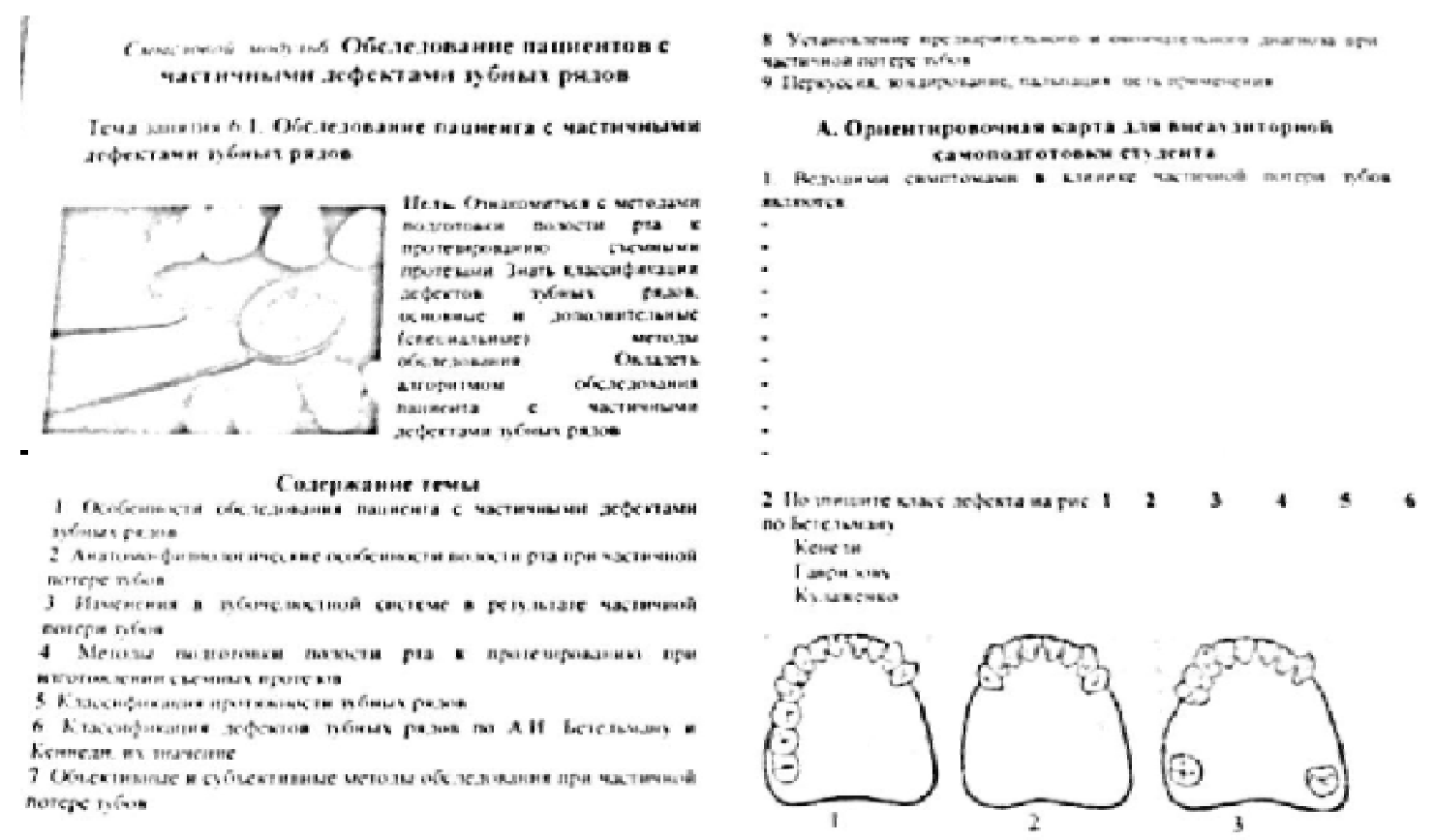

Puc. 2. Тема та зміст практичного заняття. Орієнтовна карта для позааудиторної роботи.

Орієнтовна карта для позааудиторної самопідготовки студента - це перелік завдань, які пропонуються студентам для виконання при вивченні матеріалу (2 етап навчання: осмислення інформації).

Враховуючи той факт, що на самостійну роботу студентів відводиться $1 / 3$ навчальних годин, тобто на 1,5 години практичного заняття 0,5 години підготовки самостійної роботи, завдання для самопідготовки виконані за принципом “шкільних прописів”. Студентам пропонується підписати малюнки, заповнити таблиці, вказати причинно-наслідкові зв' язки між інформаційними блоками. Це дозволяє скоротити час, що витра- 


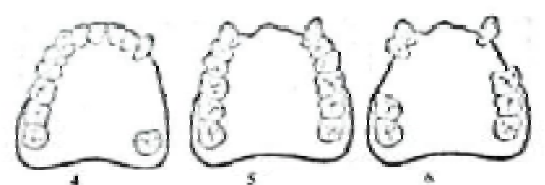

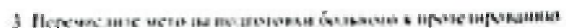

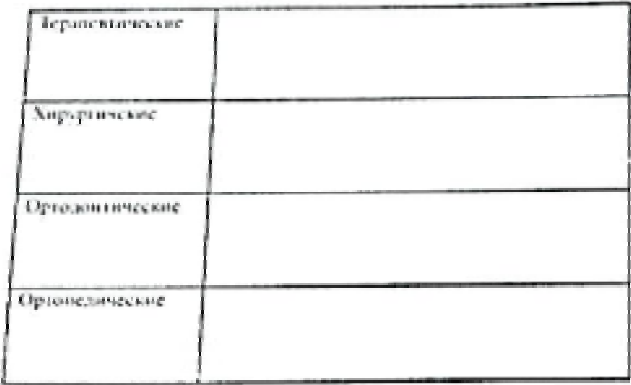

Тесовые заланин:

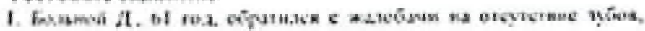

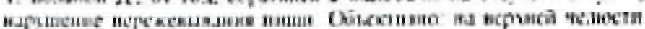

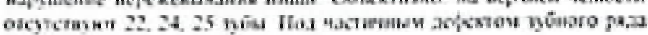

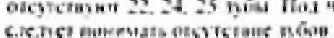

A $1=3$

II $2-3$

is $3-\mathrm{k}$

$15-$

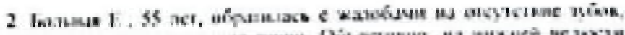

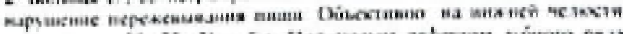

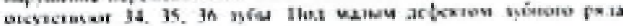

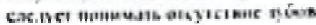

$A+1-3$

is + th

cis

1. $3-5$

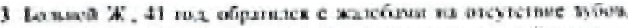

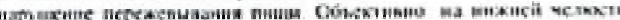

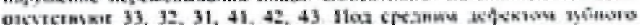

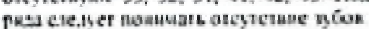

A 1.13

El +4.6

C. $2-6$

D. 7.9

E. 5-8

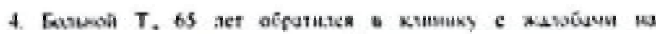

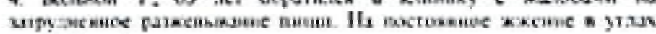

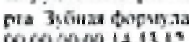

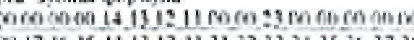

$60+7+6+5+4+3+2+13132333435363735$

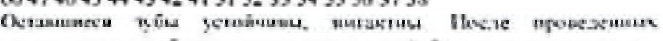

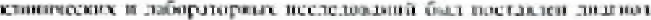

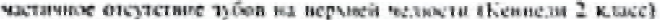

Puc. 3. Тестові завдання для підготовки студентів.

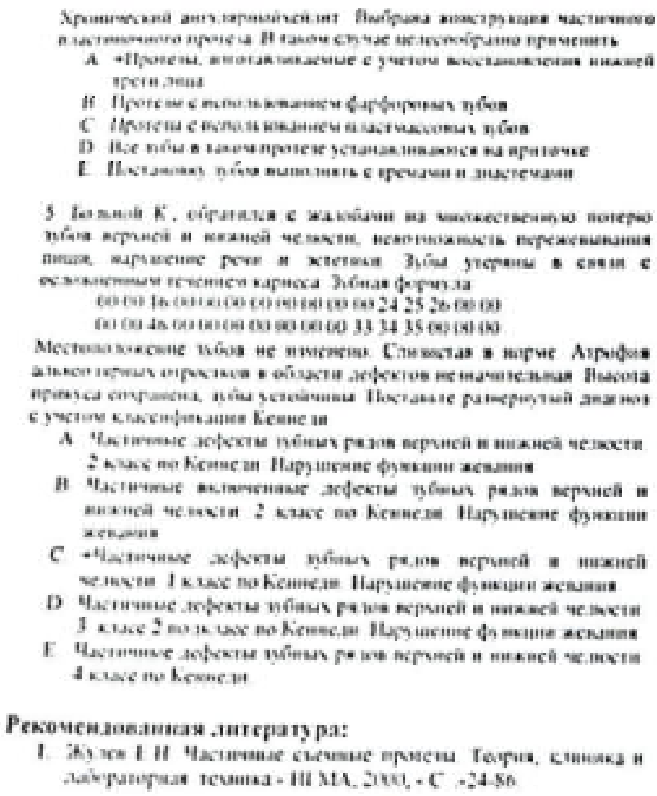

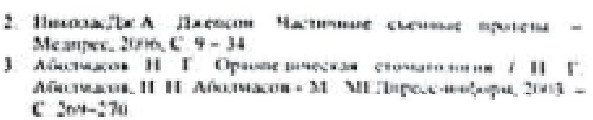

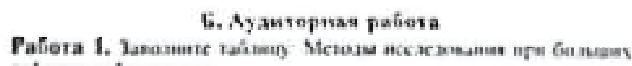

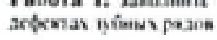

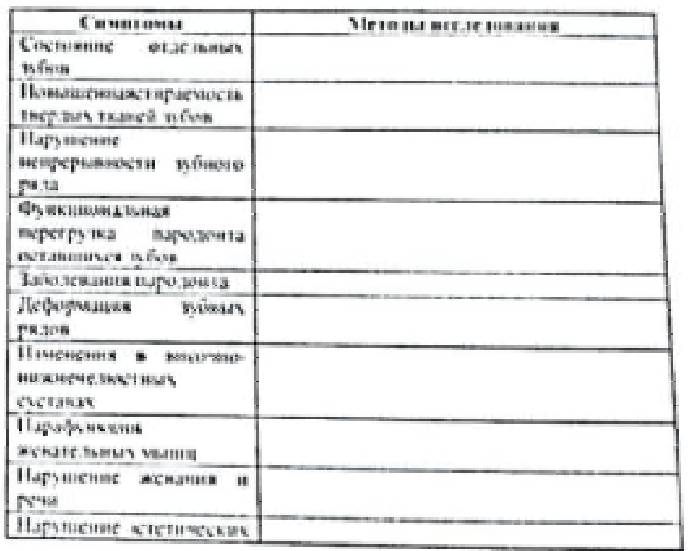

Puc. 4. Зміст аудиторної роботи.

чається на виконання завдань, зробити завдання більш цікавими, а інформацію в них більш наочною (рис. 3).

Тестові завдання підібрані з бази “Крок 2" в строгій відповідності з темою практичного заняття (рис. 3).

Ні для кого не $є$ таємницею, що для якісного результатуліцензованого тестового іспитуне достатньогарної теоретичної підготовки, а необхідно ще й навчитися працювати 3 тестовими завданнями. Вивчення тестових завдань невеликими обсягами відповідно дотем занять робить цю роботу більш ефективною, ніж “мозковий штурм в останню ніч перед іспитом".

Рекомендована література містить літературні джерела, необхідні для вивчення даної теми, використані для складання завдань "Орієнтовної карти для позааудиторної самопідготовки студента”, із зазначенням конкретних сторінок. Це також дозволяє скоротити втрати часу самопідготовки, пов'язані з пошуком інформації, що вивчається (рис. 2-3).

Аудиторна робота містить завдання, що виконуються студентами на заняттіпід контролем викладача (рис. 4). Цей розділ також містить завдання для практичних навичок з описом послідовності виконання (3 етап навчання: використання інформації для досягнення такого стану, коли студент вільно володіє нею) (рис. 5). 


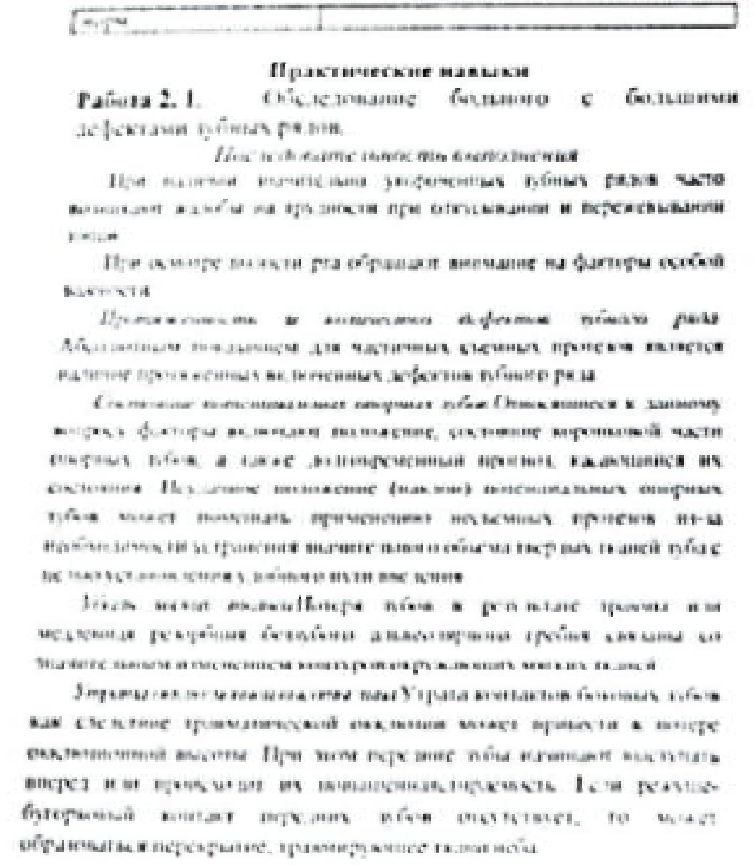

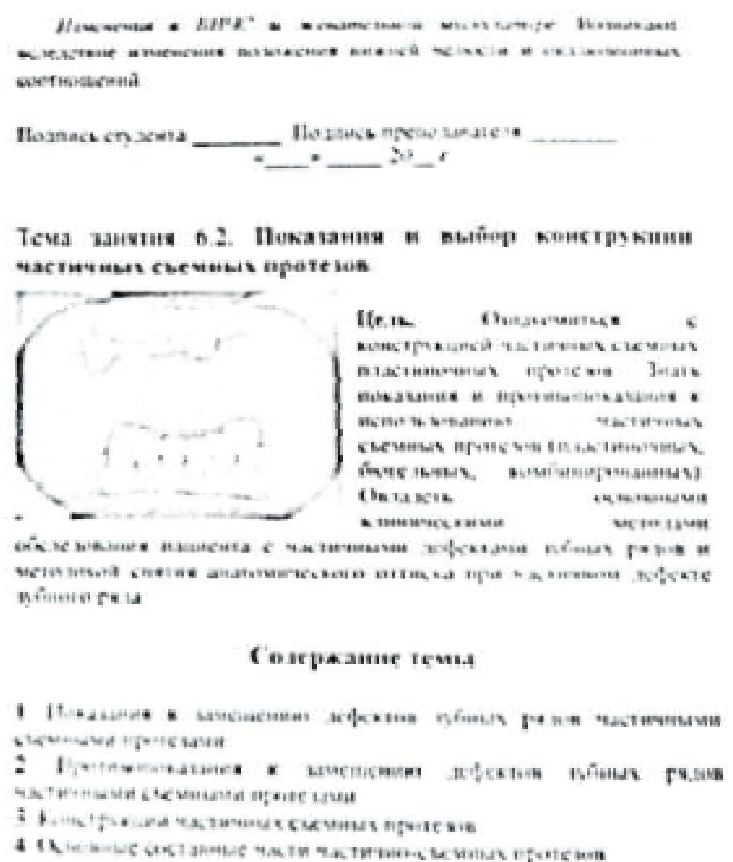

Puc. 5. Зміст практичної навички.

Оцінка поточної успішності виставляється за результатами:

1) правильності відповідей на питання в навчальному посібнику (заповнюється студентом під час підготовки до практичного заняття):

1 -виконано,

0 - не виконано;

2) співбесіди на практичному занятті:

2 - дано повну відповідь на запитання,

1 - дана неповна відповідь на питання,

0 - не дана відповідь на питання;

3) виконання практичної роботи на занятті;

1 -виконано,

0 - не виконано.

Конвертація балів у традиційні оцінки представлена в таблиці 1. Запропонована система оцінювання
Таблиця 1. Схема переведення балів у традиційну оцінку при оцінюванні знань та вмінь студентів

\begin{tabular}{|c|c|}
\hline Бали & Традиційна оцінка за 4-бальною шкалою \\
\hline 4 & "5” \\
\hline 3 & "4” \\
\hline 2 & "3" \\
\hline $1-0$ & "2" \\
\hline
\end{tabular}

поточної успішності дозволяє максимально її об’ єктивізувати, і проконтролювати якість самостійної роботи студентів при підготовці до практичних занять.

Роботи, виконані студентами під час відпрацювання практичних навичок, збираються до портфоліо (рис. 6).

Формування портфоліо переслідує такі цілі. По-перше, представлені портфоліо під час модульного контролю дозволяють екзаменатору отримати уявлен-

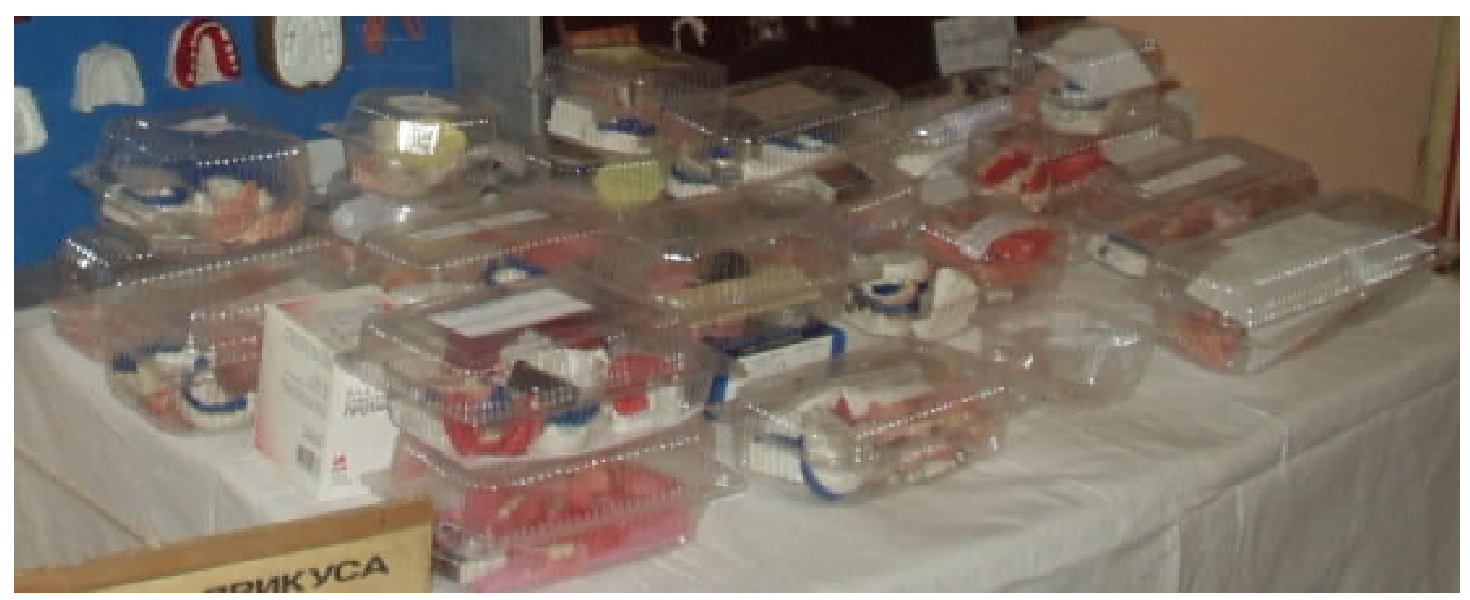

Puc. 6. Портфоліо студентів на модульному контролі. 
ня про рівень мануальних навичок студентів. Оскільки перевірити їх якість у кожного студента (30 осіб у 1 групі) протягом модульного контролю - 2 години неможливо. По-друге, виготовлені студентами фантомні роботи використовуються під час практичноорієнтованого державного іспиту для демонстрації їх мануальних навичок, таких, як фіксація коронок, зняття мостоподібних протезів, визначення центральної оклюзіi і т. д.

Під час 2 та 3 семестрів, коли студенти ще не мають достатніх знань та вмінь для виготовлення якоїнебудь конструкщії, ми пропонуємо за весь час курсу пропедевтики ортопедичної стоматології (1 рік) виготовлення двох моделей верхньої та нижньої щелепи 3 пластмасовими стандартними зубами для всіх подальших маніпуляцій на кафедрі терапевтичної

\section{Література}

1. Болюбаш Я. Я. Організація навчального процесу у вищих навчальних закладах / Я. Я. Болюбаш. - К. : ВВП “Компас", 1997. -64 с. стоматології, ортопедичної стоматології (препарування, мікропротезування).

При складних маніпуляціях (заміна воску на пластмасу, обробка, полірування) в парі зі студентами виконують студенти зуботехнічного відділення в якості напрацювання балів для виконання самостійної роботи у своєму навчанні.

Висновок. Запроваджені методи організації навчального процесу дозволили поєднати теоретичну підготовку студентів з відпрацюванням ними практичних навичок, зробили більш цікавою і наочною самостійну позааудиторну роботу студентів, дали можливість викладачам контролювати якість цієї роботи. Це дозволяє підвищити якість підготовки студентів-стоматологів як до випускних іспитів, так і для подальшої професійної діяльності.

2. Освіта : Тимчасове положення про організацію навчального процесу в кредитно-модульній системі підготовки фахівців. -2004. - № 8 (5084). 